\title{
Morphometric Aspects of the Jugular Foramen and Jugular Fossa in Dry Skulls of Central India
}

\author{
Vaibhav Prakash Anjankar¹, Bipinchandra Khade², Kanchankumar P. Wankhede³, \\ Sachin J. Patil ${ }^{4}$, Ganesh N. Trivedi' ${ }^{5}$, Vilas K. Chimurkar ${ }^{6}$
}

\begin{abstract}
${ }^{1}$ Department of Anatomy, Jawaharlal Nehru Medical College, DMIMS, Sawangi Meghe, Wardha, Maharashtra, India. ${ }^{2}$ Department of Anatomy, Chirayu Medical College, Bhopal, Madhya Pradesh, India. ${ }^{3}$ Department of Anatomy, Government Medical College, Nagpur, Maharashtra, India. ${ }^{4}$ Department of Anatomy, GAIMS, Bhuj, Gujarat, India. ${ }^{5}$ Department of Anatomy, Andaman \& Nicobar Islands Institute of Medical Sciences, Port Blair, India. ${ }^{6}$ Department of Anatomy, Jawaharlal Nehru Medical College, DMIMS, Sawangi Meghe, Wardha, Maharashtra, India.
\end{abstract}

\section{ABSTRACT}

\section{BACKGROUND}

Jugular foramen is a large irregular hiatus at the base of the skull which transmits a large number of important structures. Any abnormality of jugular foramen and associated jugular fossa may impart damage to these structures. Aim of the present study was to analyse the shape, size, presence of septa, presence of a domed bony roof and bilateral symmetry of the Jugular foramen in dry adult skulls of males and females in the central Indian population.

\section{METHODS}

A total of 120 skull jugular foramina and jugular fossae were examined, by two different researchers to avoid observer errors. Parameters studied were anteroposterior and transverse diameters of jugular foramen, width and depth of jugular fossa, presence of bony septum etc. Data was collected and analysed using statistical software.

\section{RESULTS}

Antero-posterior and transverse diameters of right jugular foramen were found to be more than left one. Complete septation of jugular foramen was observed in $1.67 \%$ and $2.5 \%$ skulls on right and left side respectively. Bony roof or dome of jugular fossa was observed in $30 \%, 17.5 \%$ and $16.67 \%$ on the right side, the left side, and bilaterally respectively. In $10.83 \%$ skulls, we found an accessory foramen connecting jugular foramen to anterior condylar canal.

\section{CONCLUSIONS}

Detailed knowledge of various anomalies of jugular fossa and jugular foramen should be kept in mind while doing surgery by neurosurgeons and ENT surgeons. Radiologists also should keep these points in the mind while interpreting CT and MRI scans.

\section{KEY WORDS}

Anthropologists, Sutures, Septum, Accessory, Condylar, Evolutionary
Corresponding Author: Dr. Vaibhav P. Anjankar. Associate Professor, Department of Anatomy, Jawaharlal Nehru Medical College, DMIMS, Sawangi Meghe, Wardha, Maharashtra, India. E-mail: vaibhav_anjankar@yahoo.co.in

DOI: $10.14260 / j e m d s / 2020 / 611$

How to Cite This Article: Anjankar VP, Khade B, Wankhede KP, et al. Morphometric aspects of the jugular foramen and jugular fossa in dry skulls of central India. J Evolution Med Dent Sci 2020;9(38):2805-2809, $10.14260 / \mathrm{jemds} / 2020 / 611$

Submission 27-04-2020,

Peer Review 30-07-2020,

Acceptance 07-08-2020,

Published 21-09-2020.

Copyright (c) 2020 JEMDS. This is an open access article distributed under Creative Commons Attribution License [Attribution 4.0 International (CC BY 4.0)] 


\section{BACKGROUND}

The various skull foramina and their morphological features remain a matter of interest and curiosity till date to anatomists, anthropologists, neurosurgeons and other researchers because of their anthropological, surgical and clinical interests.

The Jugular Foramen (JF) lies between the occipital bone and the petrosal portion of the temporal bone in the posterior end of the petro-occipital suture. ${ }^{1}$ It is long and irregularly shaped, long axis is projected antero-medially. The jugular foramen may be partially or completely divided in three compartments by bony spicules called as intrajugular process. Anterior most compartment transmit inferior petrosal sinus, the intermediate portion or neural compartment contain the glossopharyngeal, the vagus and the accessory nerves; and its posterior portion or vascular compartment contain the internal jugular vein and the meningeal branches of the ascending pharyngeal and occipital arteries.

The size and shape of jugular foramen varies in different skulls, also between two sides of the same skulls, from its intracranial to extra cranial end in the same jugular foramen. This is a unique foramen considering its complex irregular shape, its sinuous course, its formation by two bones and the numerous nerves and venous channels passing through it. ${ }^{2}$

Jugular fossa has always attracted the attention of ENT surgeons, neurologist and radiologists considering recent advances in surgical procedures involving skull base and middle ear. ${ }^{4}$ Compartmentalization of jugular foramen could be logical reason for compression of structures passing through it, especially cranial nerves leading to various symptoms called as Jugular foramen syndrome (Vernet's syndrome $)^{3}$ A tumour called as Glomus jugulare develops in the region of jugular foramen, through which Glossopharyngeal, Vagus and Accessory nerves exits. Glomus jugulare causes compression of these nerves leading to loss of hearing and paralysis of lower cranial nerves. ${ }^{3}$ The various structures that pass through jugular foramen make this foramen very special as multiple points need to be kept in mind while interpreting or operating in the structures.

Any variations in the anatomy of jugular foramen are important to neurosurgeons and ENT surgeons while they are operating in this region. Jugular foramen is also important to radiologist for interpretation of CT and MRI studies of this region. It is very interesting as well as challenging to the Anatomists to answer the queries by fellow doctors, regarding normal variations in the structure of jugular foramen. Jugular foramen shows many variations from its normal anatomy mentioned in the books.

The present study was carried out with the aim to analyse the shape, size, presence of septa, presence of a domed bony roof and bilateral symmetry of the Jugular foramen in dry adult skulls of males and females in the central Indian population.

\section{METHODS}

The present cross sectional observational study was carried out in the Department of Anatomy of our medical college from December 2014 to October 2016. The Institutional Ethical Committee approval was obtained for carrying out the study.
A total of 120 dry human skulls was included in this study. The sample size was taken at conveniences. Only adult skulls (as identified by suture closure) were included in study. Broken or malformed skulls were excluded from study. Skulls with pathological or traumatic damage were also excluded. The measurements were made by two separate researchers to avoid observer error. The mean value of two researchers was considered finally. All the measurements were taken with the help of digital vernier caliper accurate to $0.01 \mathrm{~mm}$.

\section{Parameters Studied}

Jugular Foramen:

a) Maximum antero-posterior diameter

b) Maximum transverse diameter

c) Bony septum, if any, was noted

Jugular Fossa

a) Maximum width of Jugular fossa

b) Depth of jugular fossa

c) Presence or absence of bony roof (Dome)

\section{Statistical Analysis}

The collected data was entered in Microsoft excel sheet. The statistical analysis was performed using SPSS version 11. Mean and standard deviation (SD) was calculated.

\section{RESULTS}

The jugular foramen was larger on right side in $69(57.5 \%)$ skulls and larger on left in 10 skulls. In 41 (34.17\%) skulls, both foramina were of same size (shown in Table 1). Figure 1 depicts large right jugular foramen as compared to left jugular foramen.

\begin{tabular}{|ccc|}
\hline Size of Jugular Foramen & Number of Skulls & Percentage \\
Larger right JF & 69 & $57.5 \%$ \\
Larger Left JF & 10 & $8.33 \%$ \\
Equal on both sides & 41 & $34.17 \%$ \\
\hline Table 1. Laterality of Size of Jugular Foramen (JF) \\
\hline
\end{tabular}

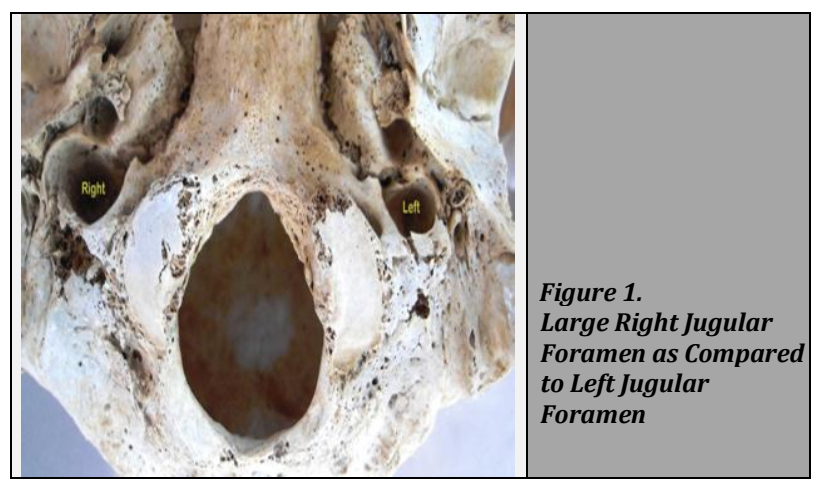

\section{Jugular Foramen}

a) Antero-Posterior Diameter of Jugular Foramen The mean AP diameter of jugular foramen (Table 2) was found to be $9.8 \pm 1.2 \mathrm{~mm}$ on right side and $7.2 \pm 1.3 \mathrm{~mm}$ on left side. The largest AP diameter observed on right side was $13.2 \mathrm{~mm}$, and $11.4 \mathrm{~mm}$ on left side. 


\begin{tabular}{|ccc|}
\hline Various Parameters Studied (in mm) & Right Side & Left Side \\
\hline Antero-Posterior Diameter of Jugular Foramen & $9.8 \pm 1.2$ & $7.2 \pm 1.3$ \\
Max. Transverse Diameter of Jugular Foramen & $14.9 \pm 1.4$ & $12.7 \pm 1.3$ \\
Maximum Width of Jugular Fossa & $8.13 \pm 1.9$ & $7.98 \pm 1.6$ \\
Depth of Jugular Fossa & $10.9 \pm 1.2$ & $10.5 \pm 1.8$ \\
\hline Table 2. Various Parameters of Jugular Foramen \\
and Jugular Fossa \\
\hline
\end{tabular}

b) Maximum Transverse Diameter of Jugular Foramen The mean transverse diameter of Jugular foramen also showed variation in measurements (on right side was $14.9 \pm 1.4 \mathrm{~mm}$ and $12.7 \pm 1.3 \mathrm{~mm}$ on left side; Table 2 ).

c) Presence of Bony Septum in Jugular Foramen Most of the literature agrees that jugular foramen is divided into three compartments by two constrictions. We observed bilateral complete septation of jugular foramen in two compartments in $3(2.5 \%)$ skulls. Complete septation of right jugular foramen was observed in $2(1.67 \%)$ skulls and left jugular foramen only was found in 3 (2.5\%) skulls. Figure 2 shows complete septation of right jugular foramen. Figure 3 shows complete septation of left jugular foramen. Incomplete unilateral septation was observed in 29 skulls [9 skulls (7.5\%) on right and 20 skulls (16.67\%) on left side]. Figure 4 shows incomplete septation of left jugular foramen. Rest of the skulls no septation with single jugular foramen.
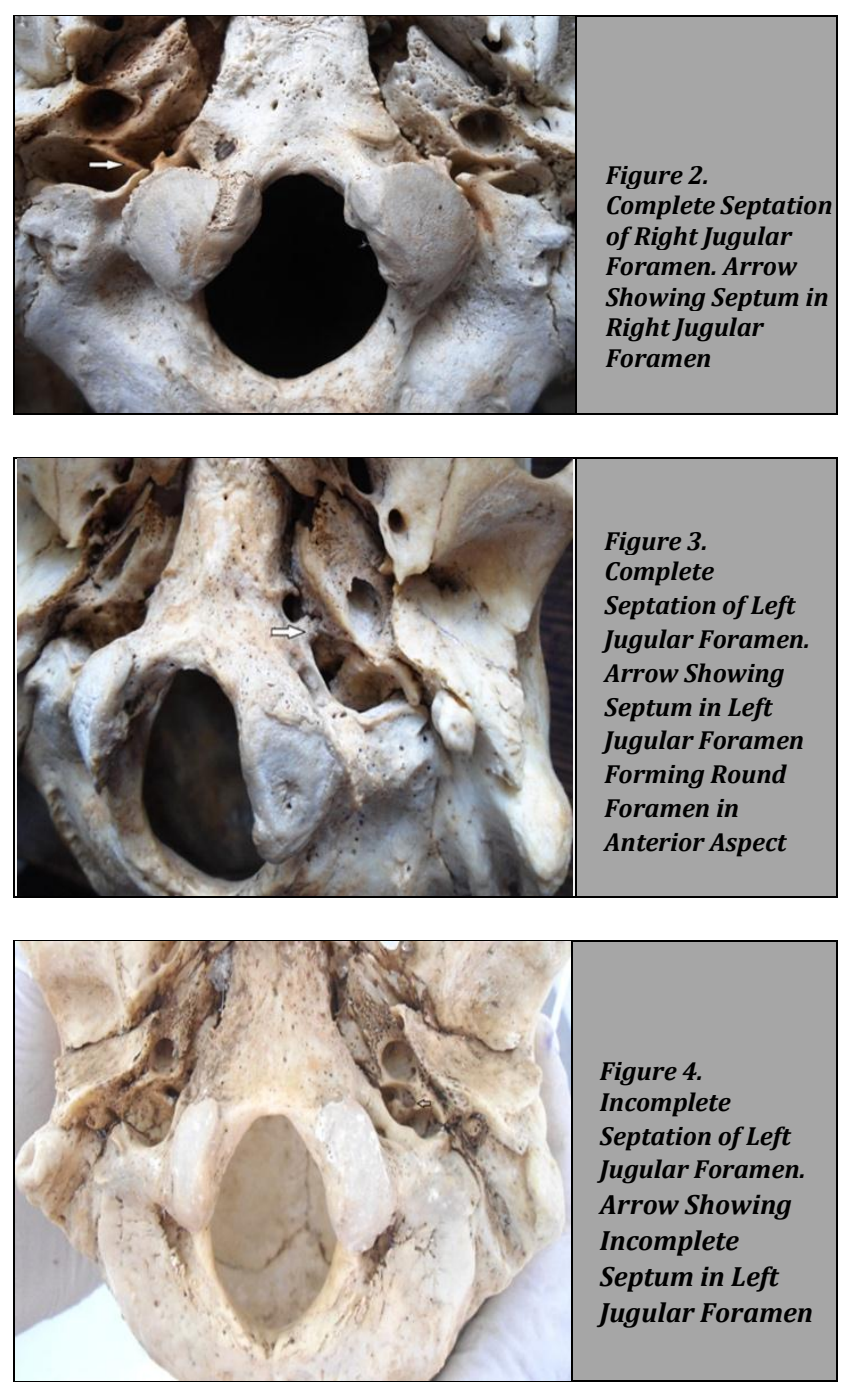

\section{Jugular Fossa}

a) Maximum Width of Jugular Fossa

The mean width of jugular fossa as observed on right side was $8.13 \pm 1.9 \mathrm{~mm}$ and on left side $7.98 \pm 1.6 \mathrm{~mm}$ (Table 2). Jugular fossae were much wider on right side than left side.

b) Bony Roof (Dome) of Jugular Fossa

The presence of bony roof or dome indicates the jugular bulb. Bony roof was observed in 36 (30\%) skulls on right side and 21 (17.5\%) skulls on left side. Bilateral dome (roof) was present in 20 (16.67\%) skulls. No dome was observed in 43 (35.83\%) skulls (Table 3).

\begin{tabular}{|cccc|}
\hline & & Number of Skulls & Percentage \\
\hline \multirow{2}{*}{$\begin{array}{c}\text { Presence of } \\
\text { Dome }\end{array}$} & Right Side & 36 & $30 \%$ \\
& Left Side & 21 & $17.5 \%$ \\
& Bilateral & 20 & $16.67 \%$ \\
\hline \multicolumn{2}{c}{ Table 3. Presence of Bony Roof (Dome) of Jugular Fossa } \\
\hline
\end{tabular}

c) Depth of Jugular Fossa

Depth was measured only when fossa has dome or bony roof. The mean depth of jugular fossa on right side was found to be $10.9 \pm 1.2 \mathrm{~mm}$ and $10.5 \pm 1.8 \mathrm{~mm}$ on left side (Table 2).

In addition to these findings; in 13 (10.83\%) skulls, we found an accessory foramen communicating jugular foramen with anterior condylar canal which was revealed by a thread passing through it. Figure 5 shows such an abnormal communication between jugular foramen and anterior condylar canal.

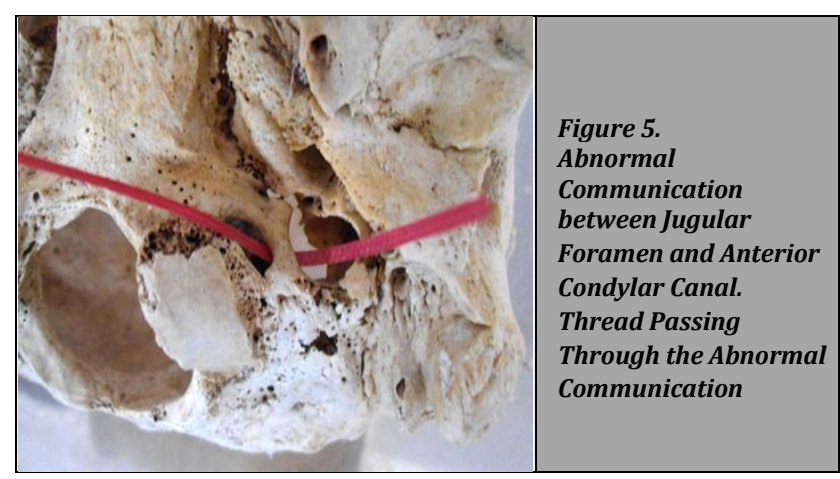

\section{DISCUSSION}

In the present study, we made a sincere attempt to study the normal anatomy of jugular foramen and jugular fossa. The shape and size of the jugular foramen is dependent on the size of the internal jugular vein and the presence or absence of a prominent superior bulb of the internal jugular vein. It is generally expected that the right jugular foramen is larger than the left, since superior sagittal sinus as draining into the right transverse sinus. ${ }^{4}$ The variations in size and shape of jugular foramen are also contributed to variations in the anatomy of intracranial venous sinuses. ${ }^{5}$ The difference in the size of two internal jugular veins is visible during development at 23 
weeks stage of embryo, which results from different developmental pattern of right and left brachiocephalic veins. ${ }^{6}$

The various values of antero-posterior diameter of jugular foramen as observed by other researchers are shown in Table 4. Our values of AP diameter are very comparable to values observed by other authors like Pereira et $\mathrm{al}^{1}{ }^{1} \mathrm{Idowu}^{7}$ and Singla et al. ${ }^{8}$ The values of transverse diameter of jugular foramen in the present study was found to be $14.9 \pm 1.4 \mathrm{~mm}$ on right side and $12.7 \pm 1.3 \mathrm{~mm}$ on left side. The values by Pereira et $\mathrm{al}^{1}$ and Singla et $\mathrm{al}^{8}$ are on higher side while values by Idowu ${ }^{7}$ are on lower side as compared to our study findings. The difference in the values may be contributed to difference human races and geographical regions in which the study was carried out. Pereira ${ }^{1}$ studied south Brazilian population, Idowu studied Nigerian population, Hatiboglu \& Anil examined Antolian skulls, Patel \& Singel carried their study in Saurashtra region and Singla et al studied Northwest Indian population. Furthermore, Wysockiet $\mathrm{al}^{9}$ quoted in their study that variations in the size of foramina are due to racial and individual factors.

\begin{tabular}{|c|c|c|c|c|}
\hline & \multicolumn{2}{|c|}{$\begin{array}{l}\text { Antero-Posterior } \\
\text { Diameter of Jugular } \\
\text { Foramen (mm) }\end{array}$} & \multicolumn{2}{|c|}{$\begin{array}{c}\text { Maximum Transverse } \\
\text { Diameter of Jugular } \\
\text { Foramen (mm) }\end{array}$} \\
\hline & Right Side & Left Side & Right Side & Left Side \\
\hline Idowu (2004) & 10.02 & 9.57 & 13.9 & 14.11 \\
\hline Pereira et al (2010) & $9.21 \pm 1.95$ & $8.67 \pm 1.57$ & $15.82 \pm 2.67$ & $15.86 \pm 2.64$ \\
\hline Singla et al (2012) & $9.32 \pm 2.04$ & $7.34 \pm 2.04$ & $15.67 \pm 2.28$ & $14.85 \pm 2.89$ \\
\hline Present study (2013) & $9.8 \pm 1.2$ & $7.2 \pm 1.3$ & $14.9 \pm 1.4$ & $12.7 \pm 1.3$ \\
\hline
\end{tabular}

We found large jugular foramen on right side in $57.5 \%$, on left side in $8.33 \%$ and in $34.17 \%$ skulls equal jugular foramen were found on both sides (Table 5). Our values were very close to that found by Hatiboglu \& Anil ${ }^{10}$ and Patel \& Singel. ${ }^{11}$ But Sturrock ${ }^{5}$ found much higher values.

\begin{tabular}{|cc|cc|}
\hline Authors & $\begin{array}{c}\text { Large JF on } \\
\text { Right Side }\end{array}$ & $\begin{array}{c}\text { Large JF on } \\
\text { Left Side }\end{array}$ & $\begin{array}{c}\text { Equal JF on } \\
\text { Both Sides }\end{array}$ \\
\hline Sturrock (1988) & $69 \%$ & $23 \%$ & $8 \%$ \\
Hatiboglu \& Anil (1991) & $61.6 \%$ & $26 \%$ & $12.33 \%$ \\
\hline Patel \& Singel (2007) & $60.4 \%$ & $15.4 \%$ & $24.2 \%$ \\
\hline Present study (2013) & $57.5 \%$ & $8.33 \%$ & $34.17 \%$ \\
\hline Table 5. Size of Jugular Foramen According to Different Researchers \\
\hline
\end{tabular}

The formation of septa helps to form bony compartments in the jugular foramen that may compress the structures passing through it. Shapiro and Robonson in their article described morphogenesis of foraminal anomalies at the base of skull. Compartmentalization of jugular foramen can be because of ongoing evolutionary process. ${ }^{12}$ There is huge variation in the percentage of compartmentalization of jugular foramen as shown in Table 6.

\begin{tabular}{|c|c|c|c|c|}
\hline & $\begin{array}{l}\text { Unilateral } \\
\text { Complete } \\
\text { Septum } \\
\text { (Right Side) }\end{array}$ & $\begin{array}{c}\text { Unilateral } \\
\text { Complete } \\
\text { Septum } \\
\text { (Left side) }\end{array}$ & $\begin{array}{c}\text { Unilateral } \\
\text { Incomplete } \\
\text { Septum } \\
\text { (Right Side) }\end{array}$ & $\begin{array}{c}\text { Unilateral } \\
\text { Incomplete } \\
\text { Septum } \\
\text { (Left Side) }\end{array}$ \\
\hline Sturrock (1988) & $3.2 \%$ & $3.2 \%$ & $1.3 \%$ & $10.9 \%$ \\
\hline $\begin{array}{l}\text { Hatiboglu \& Anil } \\
\qquad(1992)\end{array}$ & $5.6 \%$ & $4.3 \%$ & $2.6 \%$ & $19.6 \%$ \\
\hline Patel \& Singel (2007) & $23.1 \%$ & $17.6 \%$ & - & - \\
\hline Sethi et al (2011) & $17.8 \%$ & $14.3 \%$ & & \\
\hline Singla et al (2012) & $4 \%$ & - & - & - \\
\hline $\begin{array}{l}\text { Present Study } \\
\text { (2013) }\end{array}$ & $1.67 \%$ & $2.5 \%$ & $7.5 \%$ & $16.67 \%$ \\
\hline $\begin{array}{r}\text { Table } \\
\text { Jt }\end{array}$ & $\begin{array}{l}\text { mpariso } \\
\text { Ir Foram }\end{array}$ & $\begin{array}{l}\text { ompart } \\
\text { th Prev }\end{array}$ & $\begin{array}{l}\text { entalizatio } \\
\text { us Studies }\end{array}$ & \\
\hline
\end{tabular}

The width of jugular foramen is one of the important parameters as it directly reflects the size of internal jugular vein or its bulb or both. In our study, we found that mean width of jugular fossa as $8.13 \pm 1.9 \mathrm{~mm}$ on right side and $7.98 \pm 1.6$ $\mathrm{mm}$ on left side. Singla et $\mathrm{al}^{8}$ noted as 8.99 and $7.55 \mathrm{~mm}$ respectively.

Presence of bony roof or dome of jugular fossa was present in $30 \%$ and $17.5 \%$ of skulls on right and left side respectively. In the present study, bilateral bony roof was observed in 16.67 $\%$ skulls, very similar to Patel \& Singel ${ }^{11}$ who noted bilateral roof in $21 \%$ skulls. Rest other researchers recorded comparatively high values (Sturrock $53.9 \%$, Hatiboglu \& Anil $49 \%$, Singla et al $66 \%$ ).

In this study, depth of jugular fossa was found to be $10.9 \pm$ $1.2 \mathrm{~mm}$ and $10.5 \pm 1.8 \mathrm{~mm}$ respectively on right and left side. Singla et $\mathrm{al}^{8}$ recorded same as $11.11 \pm 2.96$ and $11.04 \pm 3.75$ mm respectively (ranging between 5 and $11 \mathrm{~mm}$ ). According to Anson, depth of jugular fossa ranges between 0 and $14 \mathrm{~mm}$. Singla et $\mathrm{al}^{8}$ quoted that depth may be related to high jugular bulb causing conductive deafness because of its contact with tympanic membrane causing interference with ossicular chain and obstructing round window. ${ }^{8}$ This high jugular bulb may also cause interference during cochlear implantation. High jugular bulb close to internal acoustic meatus may also impose some problems during surgical interventions for vestibular schwannomas. Accessory foramen connecting jugular foramen with anterior condylar canal can cause spread of infection.

The major limitation of our study was the small sample size. If large number of skulls would have been included, the results would change a bit. The present study put light on various aspects of jugular foramen and jugular fossa as well as added data in Indian population.

\section{CONCLUSIONS}

The jugular foramen, an important foramen at the base of the skull shows number of variations as described above. Variations may be because of different racial and geographical factors. Sound knowledge about these variations is must for anthropologists, neurosurgeons, otolaryngologists and radiologists.

Financial or Other Competing Interests: None.

\section{REFERENCES}

[1] Pereira GAM, Lopes PTC, Santos AMPV et al. Morphometric aspects of the jugular foramen in dry skulls of adult individuals in Southern Brazil. J Morphol Sci 2010;27(1):3-5.

[2] Hussain SS, Mavishetter GF, Thomas ST, et al. Morphological variations in the structure of the jugular foramen of the human skulls of south India. Biomedical Research 2010;21(4):349-50.

[3] Sethi R, Singh V, Kaul NV. Morphological variations in morphology of a jugular foramen in north Indian human adult skulls. Indian J Otol 2011;17(1):14-6. 
[4] Sturrock RR. Variations in the structure of the jugular foramen of the human skull. J Anat 1988;160:227-30.

[5] Woodhall B. Anatomy of cranial blood sinuses with particular reference to the lateral. Laryngoscope 1939;49(10):966-1009.

[6] Padget DH. The development of cranial venous system in man from the viewpoint of comparative anatomy. Contributions to Embryology 1957;36:79-140.

[7] Idowu OE. The jugular foramen - a morphometric study. Folia Morphol 2004;63(4):419-22.

[8] Singla A, Sahni D, Aggarwal A, et al. Morphometric study of jugular foramen in northwest Indian population. Journal of Postgraduate Medicine Education and Research 2012;46(4):165-71.
[9] Wysocki J, Reymond J, Skarzynski H, et al. The size of selected human skull foramina in relation to skull capacity. Folia Morphol 2006;65(4):301-8.

[10] Hatiboglu MT, Anil A. Structural variations in the jugular foramen of the human skull. J Anat 1992;189(Pt 1):1916.

[11] Patel MM, Singel TC. Variations in the structure of jugular foramen of the human skulls in Saurashtra region. J Anat Soc India 2007;56(2):34-7.

[12] Athavale SA. Morphology and compartmentation of the jugular foramen in adult Indian skulls. Surg Radiol Anat 2010;32(5):447-53. 